\title{
Effects of Colour Combination on Short-Words Processing Speed
}

\author{
Nace PUŠNIK, Anja PODLESEK, Uroš NEDELJKOVIĆ, Klementina MOŽINA
}

\begin{abstract}
In television broadcasts, important information is often conveyed with short inscriptions. In such elements, the typeface, letter case, positioning, timing and colour combinations may affect the speed of information processing to the level of recognition. It is therefore necessary to choose an appropriate combination of these properties. In the present study, we were especially interested in the effects of applied colours in connection with the above-mentioned factors. The speed of recognising three-letter words was measured in different experimental conditions where the typeface of the inscription, its position and colour combination varied. Two typefaces (i.e. Calibri and Georgia), two letter cases (i.e. upper-case and lower-case), two positions (i.e. upper left and right) and four colour combinations (i.e. white on blue, blue on white, white on red and red on white) were tested. The results showed that colour combinations affected the speed of word processing to the level of recognition.
\end{abstract}

Keywords: colour combination; letter case; position; recognition; typeface

\section{INTRODUCTION}

While watching television informative programmes, we mostly focus on the video and sound. However, some important information, e.g. the location of a certain event or the identity of the person speaking, is also conveyed through graphic elements (indications). In such elements, the typeface, letter case and position of their presentations may affect the speed of processing information to the level of recognition [1-3]. It is hence necessary to choose an appropriate combination of these properties. The present study examined to what extent, in comparison to, for example, typeface, letter case and location of indication presentation, the recognition threshold is affected by the colour combination.

The television technology has rapidly developed in terms of technological improvements [4]; however, at the same time, the area of ergonomic requirements and related graphic design has been put aside. Graphic design should receive more attention as it may affect the processing of information presented on the screen. The effect of colours in connection with appropriate typography on information processing has been studied less than expected. Both, technology and design factors, should be taken into account since both areas are important for effective exploration and implementation of improvements [5-8].

Short inscriptions can appear on a screen during television news. In most cases, they inform the viewers about the facts that could be important for them, e.g. sport results, election results, upcoming content etc. The viewer should therefore be able to receive and process the information. The latter should be presented in a way which is convenient for the user, not requiring too much effort for comprehension. Limitations can occur since short inscriptions are present on the screen for a limited period of time, during which the viewer may not be focused on the screen content. The question arises as to how short inscriptions should be presented on the screen to be processed in a minimum amount of time and with minimum attention resources. Certain typefaces and other relevant characteristics of information presentation may lead to quicker and more efficient processing than others [9-11].

Common guidelines of typeface application for titles of short duration (excl. subtitles) are somewhat vague, since there is a lack of research on the practical use of typography in this area. For this reason, the present study focused on how the shape of letters, letter case, position on the screen and especially colour combinations affect word legibility in the case of short titles presented in a limited amount of time. We studied recognition thresholds, i.e. the minimum time needed for recognition (correct recall) of the presented title. The importance of title position was pointed out by Leckner [12]; however, present study also wanted to address the role of other factors (i.e. shape of characters, colour combination) in title recognition and their interaction with the title position.

Inscriptions in news programmes are rarely shown in isolation. In practice, they are put on coloured backgrounds to increase their visibility, making them easily distinguishable from the video, which is typically essential and attracts attention to a greater extent [13-17]. The choice of colour of the text and background is not trivial. The colour combination can affect our decisions subconsciously [18]. For example, in line with the research on the applicability of colours $[19,20]$ in advertising, it is recommended that specific colours be selected to suit an individual stakeholder group. Furthermore, colour may benefit the working memory [21].

The news programmes often use a combination of white, red and blue colours (cf. Fig. 1, Examples of corporate identities of TV news), trying to achieve a good colour contrast and visibility. For example, a white (light) text is combined with a blue background (cf. Fig. 1, Panels A-B), a dark blue text is presented on a background of higher brightness (cf. Fig. 1, Panel C), a white text is presented on a red background, or vice versa (cf. Fig. 1, Panels D-F).

The method of reporting news differs between national and commercial informative programmes - commercial television stations tend to present news in a more sensational way. They may want to use red combined with white for titles, since the red colour is associated with danger, aggression or fear [28, 29]. It can activate avoidance motivation and enhance performance on detailoriented cognitive tasks [30]. In turn, it can lead to greater attention given to short inscriptions that will appear during the broadcast. On the other hand, national television channels tend to follow the principle of authenticity more, using a calm mode of providing information. Therefore, in 
many cases, they use white and blue colour combinations. The blue colour is supposed to represent trust, hope and serenity [28]. Despite the subdued tone, the combination of white and blue can affect the recipient and is a visible source of additional information [29, 31, 32].

Panel D. RTL news (RTL, 2015).

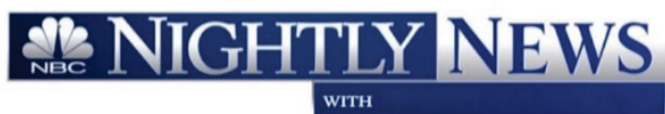

Panel B. ORF news (ORF, 2016).

Osterreich

Volumen öffentlicher Inserate geht zürück

Panel C. RTVSLO news (RTVSLO, 2014).

Varčevanje potrjeno, čas je za rast
NÄHT

HEUTE UM MITTERNACHT

Panel E. SKY news (SKY, 2015).

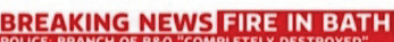

Potice

Figure 1 Examples of corporate identities of TV news

The typeface selection and the way inscriptions are presented affect recognition speed and inscription recall [10, 33-36]. For presenting inscriptions on LCD screens, it would be advisable to select typefaces that are primarily derived from the group of linear typefaces. However, the use of serif typefaces does not present a problem [37, 38], since modern technology can use along with the linear typefaces also serif typefaces which were originally designed for the screen. In the past, serifs (additional elements on letters), especially serifs in the form of thin lines, could cause problems, since they represent relatively small parts of letters that the television technology has not been able to display adequately $[35,38]$. In addition to the typeface selection, an important aspect of displaying letters is the size of letters and letter case. The latter is related to the decision about the use of lower vs. upper-case letters $[3,9,38-40]$. Due to their structure, upper-case letters occupy a larger area, which is to be an advantage. Uppercase letters are due to their size more visible. Information should hence be more quickly detected and processed to the level of word recognition and also more correctly recalled from the memory. On the other hand, words in lower-case letters form a shape which at fast reading significantly contributes to the understanding of what we read. Our previous study [3] showed that upper-case letters are processed faster compared to lower-case letters when both are presented in the same size. However, the difference in the processing speed diminishes when the $\mathrm{x}$ height of lower-case letters is increased to the size of upper-case letters [40]. When the x-height of lower-case letters is increased, the legibility of letters becomes comparable to the one of upper-case letters.

On the television screen, inscriptions can be placed in four positions in the corners of the screen (i.e. the most common practice). The most common positions in practice are the bottom left and right, and the top left and right corner. Most often, in the lower left position, information about the person on the screen (name and surname, sometimes their profession, education, job etc.) is presented during the broadcast. The question arises why the inscriptions are typically shown at the bottom and not at the top of the screen [41-43]. When considering the actual position of the viewer in front of the television screen, the viewer's eyes are often aligned with the upper rather than the lower half of the screen [34, 44, 45]. If looking straight ahead, the apparent path the viewer must make to see and read the inscription in the upper part of the screen is shorter, which is why short titles presented at the top of the screen could be processed more efficiently [46-48].

The aim of our study was to determine how colour combinations affect the legibility of short inscriptions presented on an LCD screen. In controlled laboratory conditions, short titles were presented in the upper part of the screen for a limited time. The recognition threshold, i.e. the minimum time needed for short titles to be detected, recognised and reported (repeated) correctly, was measured in different experimental conditions. The aim of the study was to examine recognition thresholds with different colour combinations. Four colour combinations were tested, two positives (red on white and blue on white) and two inverses (white on red and white on blue). Additionally, the effects of variations in typeface (serif vs. sans-serif typefaces), letter case (lower vs. upper-case style) and position on the screen (upper left, upper right corner) were taken into consideration. We wanted to examine if these additional factors interact with the effects of colour combinations on the legibility of short titles.

\section{METHOD}

In the experiment, we used a 2 (typefaces: Calibri, Georgia) $\times 2$ (letter cases: upper, lower) $\times 2$ (positions: top left, top right corner of the screen) $\times 4$ (colour combinations: blue-on-white, red-on-white, white-on-blue, white-on-red combinations) repeated-measures experimental design, which resulted in 32 experimental conditions.

Due to a large number of experimental conditions, the experiment needed to be split into two experimental sessions. One session was composed of upper-case letter conditions, while the other session was composed of lower- 
case letter conditions. There was a two days' interval between the two sessions. The participants were randomly split into two groups. One group of participants took part first in the session with a lower-case style and then in two days, it continued with the second session that contained upper-case letter conditions. The other group participated in the sessions in reverse order. To achieve optimally objective data, the effect of memory needed to be minimized for the first testing not to influence the results of the second testing.

Our experiment included short captions (or short words); all the presented words were meaningful and were taken from Dictionary of Slovene Literary Language. The purpose of comparing both types of typefaces was to determine if they differ in recognition time (legibility) also when presenting short words instead of extensive text, for which the dominance of serif typefaces is well known [49, 50].

A constant number of letters composing the words guaranteed that the area covered was comparable within lower-case letter words (and within upper-case letter words) [51]; the extent of the coverage area varied only due to the shape of letters [52]. Since our experiment was connected strictly to the use of typefaces for short inscriptions which are presented on the television screen, our focus was the letter size which is appropriate for the on-screen presentation. In our case, other effects (colour, position) were involved to see how all these variables affect (according to the typeface) the processing speed when controlling fast reading. Some findings are similar (e.g. better usefulness of serif typefaces); however, the main difference is in the presented time interval. When reading a longer text (book, ingredients), the user can decide for how long the text will be presented, whereas in the case of short inscriptions, the presentation time is limited. Therefore, the effect of all variables connected in this research is important.

We examined the legibility of the sans serif (Calibri) and serif (Georgia) typeface (cf. Fig. 2). Despite belonging to different classification groups of typefaces, they have some common characteristics, e.g. they have a comparable level of $\mathrm{x}$-height and they were both designed for use onscreen. The typefaces were tested in bold version (both typefaces in size of $40 \mathrm{px}$ ). A larger number of points/pixels has a positive effect on visibility $[53,54]$.

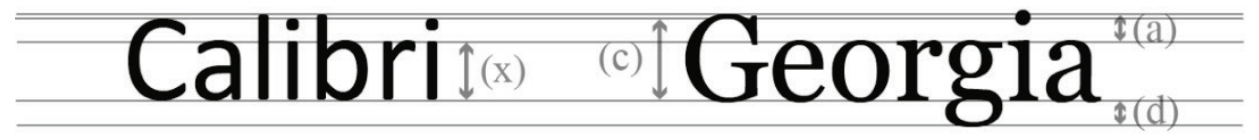

(x) $\mathrm{x}$-height

(c) capital height

Figure 2 Typefaces
The tested colour combinations were composed of three colours (hex values are given in brackets): white (\#fffff), red (\#ff0000) and blue (\#0000ff), similar to the research by Humar et al. [55]. The four colour combinations (red on white, blue on white, white on red, and white on blue) and the typefaces in the tests are shown in Fig. 3 (the same three colours can be seen in Fig. 1; these colours being in use might have ecological validity).

Calibri Bold

\section{Georgia Bold}

\section{ESGakj}

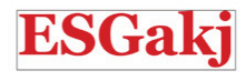

\section{ESGakj} ESGakj ESGakj ESGak] ESGakj

Figure 3 Examples of used colour combinations and typefaces

The words were presented on an LCD screen (HP ZR24w) with the resolution of $1920 \times 1200$ pixels and pixel pitch of $0.270 \mathrm{~mm}$ (distance between the centres of two pixels), visual angle of a pixel was $0.0259^{\circ}$ (1' 33.24"). The screen had $60 \mathrm{~Hz}$ refresh rate and included an antiglare filter. At these conditions, the letters and their parts were perceptually smooth in both typefaces, i.e. serif and non-serif ones. Since the screen resolution was high, letters did not have a jagged effect noticed by the naked eye. Both (a) ascender (d) descender

typefaces have an appropriate counter shape, which helps with a clear presentation of letters on a screen.

Since in the study by McCalley [56], participants had difficulties when the testing was done with the moving background picture and since using different dynamic background videos could affect the recognition of inscriptions, we chose to hold the testing conditions constant and decided to use the grey background of the screen.

The lighting conditions in the experiment were in accordance with the standards ISO 3664:2009 [57] and ISO 9241-307:2008 [58]. The first standard was used for the lighting conditions of the surrounding (set to neutral grey colour and with reflectivity minimal according to the standard) and the second was applied to control the lighting conditions of the screen. The resulting luminance of the LCD screen was between 80 and $160 \mathrm{~cd} / \mathrm{m}^{2}$. We did not put excessive emphasis to visual acuity, since we assumed that the surrounding of the room the experiment took place in is appropriate for a larger group of participants.

According to usability studies [59-61], twenty observers (10 females and 10 males with the average age of 25.1 years) participated in the experiment. All of them had according to their reports normal or corrected-tonormal vision (either wore glasses or contact lenses). No major difficulties with eyes were reported. The observers were given 10 minutes to adapt to the surrounding conditions of the laboratory before the experiment started. During this time, the experimental procedure was explained to the participants. Before the start of the experiment, instructions were also written on the screen, 
where the participants were able to read them once again. The design was a within-subjects experimental design; therefore, individual differences were constant across experimental conditions. The participants were asked about their eye health and no one mentioned major eye problems. Furthermore, different people watch television at home, in pubs, local shops, on a big or a small screen, on a mobile phone, tablet etc. The viewing conditions in such situations are not appropriate according to standards.

The distance between the participant and the screen was $65 \mathrm{~cm}$ and was constant for all participants (according to the instructions of the manufacturer, the approximate distance of $65 \mathrm{~cm}$ should result in the coverage of the entire measured area). The distance was measured before the experiment and controlled during the experiment with the help of an eye-tracking device TOBII X120, which has the ability to check the appropriate distance between the participant and the screen before each trial. Before the eye tracking recording started, the user was taken through the calibration procedure (Tobii Studio, User's Manual, Version 3.4.5; [62]). The participants were instructed to look at the fixation point that appeared in the centre of the screen at the beginning of each trial. $250 \mathrm{~ms}$ later, the fixation point disappeared and the chosen word appeared at one of the two positions on the screen. The participants were instructed not to move during the experiment. Some of them, however, moved their head or the upper part of the body too extensively. These data were hence not considered in the analysis.

Within each experimental session, the staircase method series for measuring the recognition threshold in 16 experimental conditions were intermixed randomly. For each trial, the word was chosen randomly without replacement out of the pool of 200 three-letter words. When the entire pool was used up, a new sampling started. With some participants, the same word was presented twice within a single series; however, this was hardly ever the case. The $150 \mathrm{~ms}$ recognition threshold is a consequence of the fact that the words were not presented at the fixation point, but in the visual periphery. All presented words were $195 \mathrm{~mm}$ away from the centre of the screen. The vertical distance between the centre of the screen and the centre of the presented word covered $8.3^{\circ}$ of the visual angle, and the horizontal distance covered $14.7^{\circ}$ of the visual angle. Therefore, words were presented approx. $16.9^{\circ}$ of the visual angle away from the fixation point, in the upper left or upper right position on the screen. No cue was given to the participants where the next word was going to be presented. Due to the fact that attention was first focused to the fixation point and later when the stimulus appeared needed to be shifted towards a new location, $150 \mathrm{~ms}$ recognition times seem reasonable. For example, Carlson et al [63] found that latencies for orienting towards a peripheral stimulus being cued were around $140 \mathrm{~ms}$ (even though in their study participants needed to make only a $7^{\circ}$ shift, the visual task they had to perform required higher processing precision).

We decided to choose the staircase method, as this method usually gives the estimation of the threshold very quickly, e.g. in 20-25 trials per experimental condition. If we wanted to try to derive recognition accuracy measures for each individual, this would mean that for each of different durations of the word presentation, at least 50 trials should be conducted to determine recognition accuracy with high enough precision (2-percent precision). Since the differences between experimental conditions were expected to be very small and lower than 2-percent precision in estimating recognition accuracy, we decided to rather use the staircase method, which is among the most used adaptive methods in psychophysics. Being adaptive, it can also take into account (and adapt to) inter-individual differences, which is typically not the case with the classic accuracy measures.

For each experimental condition, the percentage of correct recognitions of words with different durations was calculated for all participants. In separate analyses, individual recognition thresholds obtained in different experimental conditions were entered into the analysis of variance to examine the effects of independent variables.

\section{RESULTS AND DISCUSSION}

Words had to be presented for approx. $150 \mathrm{~ms}$ on the screen to be correctly recognized. The average recognition threshold in different experimental conditions was 150.2 $\mathrm{ms}(S D=12.3 \mathrm{~ms})$. Fig. 4 shows the group total percentage of correct recalls in different experimental conditions. The fastest increase in the recognition curve was obtained in the condition where white upper-case letters were presented on a blue background. Recognition was worst at the uppercase red-on-white condition.

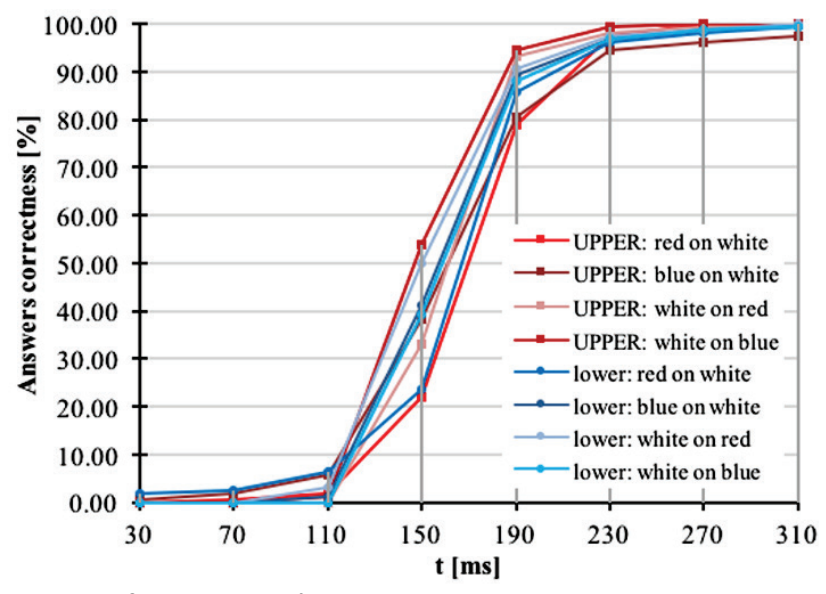

Figure 4 Correct answers for all participants in eight experimental conditions

We wanted to assess the effects of the four examined factors (i.e. colour combination, typeface, letter case and position) on the recognition threshold. Prior to performing the four-way repeated-measures analysis of variance, we took into account the fact that the words we used in our measurements covered different word areas. Since it was found in one of our previous studies that the recognition threshold is negatively correlated with the word surface area $[3,40]$, we first used the linear regression analysis and predicted the recognition threshold based on the word area, and then performed ANOVA on the residuals, i.e. on the differences between the observed and predicted recognition threshold. The analysis of the residuals enabled us to study the effect of the factors of our interest with a simultaneous control of the word surface area. The results of ANOVA of the residuals are shown in Tab. 2. Where the sphericity assumption was violated, the GreenhouseGeisser correction of degrees of freedom was used. 
Table 1 Descriptive statistics of residuals (remaining after effect of word area was eliminated from recognition thresholds) (in ms) for different experimental conditions

\begin{tabular}{|c|c|c|c|c|c|c|c|c|c|c|}
\hline \multirow{3}{*}{$\begin{array}{l}\text { Colour combination } \\
\text { (Text/background) }\end{array}$} & \multicolumn{4}{|c|}{ Top left } & \multicolumn{4}{|c|}{ Top right } & \multirow{2}{*}{\multicolumn{2}{|c|}{ Average }} \\
\hline & \multicolumn{2}{|c|}{ Calibri } & \multicolumn{2}{|c|}{ Georgia } & \multicolumn{2}{|c|}{ Calibri } & \multicolumn{2}{|c|}{ Georgia } & & \\
\hline & $M$ & $S D$ & $M$ & $S D$ & $M$ & $S D$ & $M$ & $S D$ & $M$ & $S D$ \\
\hline \multicolumn{11}{|l|}{ Lower-case } \\
\hline Red/white & -9.9 & 19.2 & -11.8 & 24.9 & -6.5 & 25.3 & -2.5 & 18.5 & -7.7 & 22.1 \\
\hline Blue/white & -5.8 & 30.7 & -20.5 & 23.2 & -8.4 & 29.1 & -12.6 & 21.0 & -11.8 & 26.4 \\
\hline White/red & -0.6 & 17.9 & -0.1 & 18.3 & 8.7 & 18.1 & 12.7 & 17.3 & 5.2 & 18.5 \\
\hline White/blue & -0.6 & 23.8 & -12.9 & 21.1 & 5.2 & 17.8 & -3.2 & 18.6 & -2.9 & 21.1 \\
\hline Average & -4.2 & 23.3 & -11.3 & 22.8 & -0.25 & 23.8 & -1.4 & 20.7 & -4.3 & 23.0 \\
\hline \multicolumn{11}{|l|}{ Upper-case } \\
\hline Red/white & 9.8 & 24.3 & 20.3 & 21.3 & -10.6 & 31.5 & 0.6 & 23.6 & 5.0 & 27.5 \\
\hline Blue/white & 9.7 & 19.8 & 7.2 & 22.2 & -11.4 & 29.5 & -3.9 & 28.0 & 0.4 & 26.2 \\
\hline White/red & 21.5 & 20.9 & 12.0 & 18.3 & 4.0 & 18.2 & 4.0 & 21.1 & 10.4 & 20.6 \\
\hline White/blue & 11.8 & 21.9 & 15.9 & 23.9 & 4.7 & 19.5 & -2.9 & 27.4 & 7.4 & 24.0 \\
\hline Average & 13.2 & 21.9 & 13.9 & 21.7 & -3.3 & 26.1 & -0.6 & 24.9 & 5.8 & 24.9 \\
\hline
\end{tabular}

Table 2 Results of ANOVA of recognition threshold

\begin{tabular}{|c|c|c|c|c|c|c|c|}
\hline Source of variability & $S S$ & $d f$ & $M S$ & $F$ & $p$ & $\eta_{\mathrm{p}}^{2}$ & Results of post-hoc comparisons \\
\hline $\mathrm{T}$ & 231.49 & 1 & 231.49 & 0.98 & .758 & 0.00 & \multirow{4}{*}{ Lower-case $<$ upper-case } \\
\hline Error $(\mathrm{T})$ & 45053.65 & 19 & 2371.25 & & & & \\
\hline $\mathrm{LC}$ & 16289.52 & 1 & 16289.52 & 56.98 & .000 & 0.75 & \\
\hline Error (LC) & 5431.58 & 19 & 285.87 & & & & \\
\hline $\mathrm{P}$ & 2925.40 & 1 & 2925.40 & 4.46 & .048 & 0.19 & \multirow{2}{*}{ Top right $<$ top left } \\
\hline Error $(\mathrm{P})$ & 12462.93 & 19 & 655.94 & & & & \\
\hline $\mathrm{CC}$ & 15630.57 & 3 & 5210.19 & 4.82 & .005 & 0.20 & \multirow{2}{*}{ Blue on white $<$ White on red } \\
\hline Error $(\mathrm{CC})$ & 61636.68 & 57 & 1081.35 & & & & \\
\hline $\mathrm{T} \times \mathrm{LC}$ & 1382.37 & 1 & 1382.37 & 5.16 & .035 & 0.21 & \\
\hline Error $(\mathrm{T} \times \mathrm{LC})$ & 5093.48 & 19 & 268.08 & & & & \\
\hline $\mathrm{T} \times \mathrm{P}$ & 649.92 & 1 & 649.92 & 1.57 & .225 & 0.08 & \\
\hline Error $(\mathrm{T} \times \mathrm{P})$ & 7855.36 & 19 & 413.44 & & & & \\
\hline $\mathrm{T} \times \mathrm{CC}$ & 3181.04 & 3 & 1060.35 & 2.11 & .110 & 0.10 & \\
\hline Error $(\mathrm{T} \times \mathrm{CC})$ & 28714.99 & 57 & 503.77 & & & & \\
\hline $\mathrm{LC} \times \mathrm{P}$ & 20000.59 & 1 & 20000.59 & 39.17 & .000 & 0.67 & \\
\hline Error $(\mathrm{LC} \times \mathrm{P})$ & 9700.96 & 19 & 510.58 & & & & \\
\hline $\mathrm{LC} \times \mathrm{CC}$ & 1420.24 & 1.80 & 790.33 & 1.67 & .205 & 0.08 & \\
\hline Error $(\mathrm{LC} \times \mathrm{CC})$ & 16139.26 & 34.14 & 472.69 & & & & \\
\hline $\mathrm{P} \times \mathrm{CC}$ & 1086.16 & 3 & 362.05 & 0.81 & .493 & 0.04 & \\
\hline Error $(\mathrm{P} \times \mathrm{CC})$ & 25448.81 & 57 & 446.47 & & & & \\
\hline $\mathrm{T} \times \mathrm{LC} \times \mathrm{P}$ & 154.89 & 1 & 154.89 & 0.36 & .556 & 0.02 & \\
\hline Error $(\mathrm{T} \times \mathrm{LC} \times \mathrm{P})$ & 8189.83 & 19 & 431.04 & & & & \\
\hline $\mathrm{T} \times \mathrm{LC} \times \mathrm{CC}$ & 2264.84 & 3 & 754.95 & 2.06 & .115 & 0.09 & \\
\hline Error $(\mathrm{T} \times \mathrm{LC} \times \mathrm{CC})$ & 20872.08 & 57 & 366.18 & & & & \\
\hline $\mathrm{LC} \times \mathrm{P} \times \mathrm{CC}$ & 337.85 & 3 & 112.62 & 0.29 & .834 & 0.02 & \\
\hline Error $(\mathrm{LC} \times \mathrm{P} \times \mathrm{CC})$ & 22275.15 & 57 & 390.79 & & & & \\
\hline $\mathrm{P} \times \mathrm{T} \times \mathrm{CC}$ & 1073.19 & 3 & 357.73 & 0.94 & .427 & 0.05 & \\
\hline Error $(\mathrm{P} \times \mathrm{T} \times \mathrm{CC})$ & 21686.16 & 57 & 380.46 & & & & \\
\hline $\mathrm{T} \times \mathrm{LC} \times \mathrm{P} \times \mathrm{CC}$ & 614.48 & 1.94 & 316.38 & 0.51 & .602 & 0.03 & \\
\hline Error $(\mathrm{T} \times \mathrm{LC} \times \mathrm{P} \times \mathrm{CC})$ & 23073.85 & 36.90 & 625.26 & & & & \\
\hline
\end{tabular}

Note: T-Typeface, LC-Letter Case, P-Position, CC-Colour Combination

Tab. 1 shows the average residuals in different experimental conditions. The larger the average residual in the experimental condition, the longer the recognition time and the slower the speed of processing the stimuli to the level of recognition. The results in Tab. 1 do not completely correspond to those presented in Fig. 4. It needs to be kept in mind that Fig. 4 and Tab. 1 show different data - the raw percentage of correct recognitions at different durations of word presentation (cf. Fig. 4) vs. the average residuals taking into account the word area (cf. Tab. 1). We decided to focus on the latter when determining which of the studied factors affects the recognition threshold.

As it can be seen in Tab. 2, letter case, position and colour combination had a statistically significant effect on the recognition threshold. The interaction between the typeface and letter case was also statistically significant, as well as the interaction between the letter case and position. When upper-case words were presented in the top left and top right position, the average recognition threshold residuals were $13.5 \mathrm{~ms}$ and -1.9 , respectively, and when lower-case words were presented in the top left and top right position, the average recognition threshold residuals was $-7.8 \mathrm{~ms}$ and -0.9 , respectively. Therefore, the difference between the two positions was greater for the upper-case words than for the lower-case words (indicating the $\mathrm{LC} \times \mathrm{P}$ interaction). Overall, the average residuals were larger for the top left position $(2.9 \mathrm{~ms})$ than for the top right position $(-1.4 \mathrm{~ms})$, indicating the main effect of position words were processed faster in the top right position compared to the top left position. Additionally, words were processed faster when written in lower-case letters (average residual was $-4.3 \mathrm{~ms}$ ) than when written in uppercase letters (average residual was $5.8 \mathrm{~ms}$ ).

With regard to the $\mathrm{LC} \times \mathrm{T}$ interaction, the upper-case words were processed faster (average residual was $4.9 \mathrm{~ms}$ ) when written in Calibri than when written in Georgia (average residual was $6.7 \mathrm{~ms}$ ), whereas the lower-case letters were processed faster when written in Georgia (average residual was $-6.4 \mathrm{~ms}$ ) compared to Calibri 
(average residual was $-2.2 \mathrm{~ms}$ ). The overall difference between the two typefaces was not substantial and was not statistically significant (average residual was $1.3 \mathrm{~ms}$ for Calibri compared to $0.1 \mathrm{~ms}$ for Georgia).

Colour combination had a statistically significant main effect on the recognition threshold. The overall average residual was $-1.3 \mathrm{~ms}$ for the red-on-white, $-5.7 \mathrm{~ms}$ for the blue-on-white, $7.8 \mathrm{~ms}$ for the white-on-red and $2.2 \mathrm{~ms}$ for the white-on-blue colour combination. Therefore, across the position and typeface, blue-on-white words were processed the fastest, followed by the red-on-white colour combination, and in conditions with negative colour combinations, longer times were needed for word recognition. The Sidak post hoc test showed that among all possible pairwise differences, only the difference between the blue-on-white and the white-on-red colour combinations reached statistical significance.

\section{CONCLUSION}

In this study, we wanted to determine what impact colours have on the recognition speed of short titles presented in the upper part of the LCD screen. The effect of typographic properties was also taken into account. We found that in general, words were processed faster when shown in lower-case style. For the words presented in the left upper part of the screen, the difference between the recognition thresholds for lower- and upper-case words was substantial, whereas for the words presented in the right upper part of the screen, the difference was very insignificant.

The main concern of this study was the effect of colour combination on recognition thresholds. Positive colour combinations (more specifically, the colour combination blue on white) were processed faster than negative colour combinations (white on red). This could be explained with the effect of luminance contrast on the reading performance. A higher level of luminance contrast enhances the reading performance [18]. In the blue-onwhite colour combination, the luminance of characters was low and the luminance of the background was high. Therefore, the luminance contrast was high. According to Humar et al. [55], who used comparable stimuli (cf. Fig. 4), the luminance contrast, calculated as the Michelson contrast, was 0.89 . In the red-on-white colour combination, the luminance of both characters and the background was high and the luminance contrast was lower (its value was 0.76) compared to the blue-on-white colour combination. This resulted in worse reading performance. Furthermore, global luminance processing might have had some influence on the processing of the target word [64]. The screen was light grey and the luminance contrast between the characters and the grey background was larger in the blue-on-white colour combination than in the white-on-red colour combination [65]. Higher contrasts result in better performance, regardless of the text colour [66]. A moderate or even a high colour contrast does not guarantee quick visual perception [21] if the luminance contrast between the characters and background is small [67]. Our study shows that when the processing of stimuli needs to be fast, the choice of colour for the text and the background to ensure good luminance contrast is imperative.

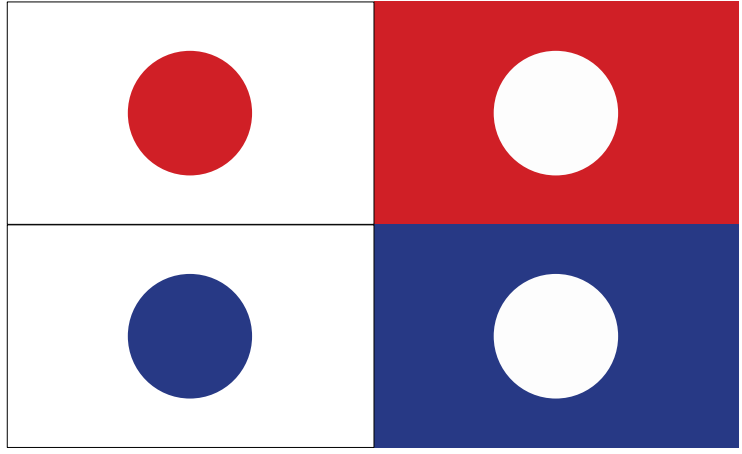

Figure 5 Practical examples of same size circles on light and dark background

A limitation of this study is that only two typefaces and two positions were studied. Nevertheless, typefaces representative of two different large groups of typefaces were used. Moreover, the used size of letters can represent a limitation. Further research should involve smaller sizes of letters. Also, short inscriptions were only presented in the upper left and right positions of the screen. These positions were chosen since in many west European countries, the lower part of the screen is reserved for presenting subtitles (e.g. in movies or in news for viewers with hearing disabilities). Thus, all other short information should be located in the upper screen positions to avoid the overlapping of subtitles and short inscriptions. Another limitation which has to be mentioned is the static background picture. To limit the number of independent variables, we decided to test short inscriptions on a static background. Further investigation should consider developing comparable dynamic background pictures and testing short inscriptions on such backgrounds.

We found that the colour combination (positive or inverse) significantly contributes to the speed of processing short titles to the level of recognition. With an appropriate colour selection and colour combinations, we can aid fast processing of information presented on the screen, which is important especially when information is presented for a limited amount of time. The results of our study indicate that a high luminance contrast between the letters and global, not merely local background, lead to faster processing of information.

\section{REFERENCES}

[1] Treurniet, W. C. (1980). Spacing of characters on a television display. Processing of Visible Language, 365-374. https://doi.org/10.1007/978-1-4684-1068-6_26

[2] Legge, G. E., Mansfield, J., \& Chung, S. T. (2001). Psychophysics of reading. Vision Research, 41(6), 725-743. https://doi.org/10.1016/s0042-6989(00)00295-9

[3] Pušnik, N., Možina, K., \& Podlesek, A. (2016). Effect of typeface, letter case and position on recognition of short words presented on-screen. Behaviour \& Information Technology, 35(6), 442-451. https://doi.org/10.1080/0144929x.2016.1158318

[4] Besuijen, K. \& Spenkelink, G. P. (1998). Standardizing visual display quality. Displays, 19(2), 67-76. https://doi.org/10.1016/s0141-9382(98)00039-0

[5] Nes, F. V. (1986). A new teletext character set with enhanced legibility. IEEE Transactions on Electron Devices, 33(8), 1222-1225. https://doi.org/10.1109/t-ed.1986.22646

[6] Nes, F. L. (1986). Space, colour and typography on visual display terminals. Behaviour \& Information Technology, 5(2), 99-118. https://doi.org/10.1080/01449298608914504 
[7] Leeuwen, T. V. (2005). Typographic meaning. Visual Communication, 4(2), 137-143. https://doi.org/10.1177/1470357205053749

[8] Možina, K., Majnarić, I., \& Rat, B. (2016). Label legibility influenced by different number of white ink layers. Tehnicki vjesnik - Technical Gazette, 23(3), 775-781. https://doi.org/10.17559/tv-20150312204707

[9] Legge, G. E., \& Bigelow, C. A. (2011). Does print size matter for reading? A review of findings from vision science and typography. Journal of Vision, 11(5), 1-22. https://doi.org/10.1167/11.5.8

[10] Franken, G., Podlesek A., \& Možina, K. (2015). Eyetracking study of reading speed from LCD displays: Influence of type style and type size. Journal of Eye Movement Research, 8(1), 1-8. https://doi.org/10.16910/jemr.8.1.3

[11] Puškarević, I., Nedeljković, U., Dimovski, V., \& Možina, K. (2016). Eye tracking study of attention to print advertisements: effects of typeface figuration. Journal of eye movement research, 9(5), 1-18. https://doi.org/10.16910/jemr.9.5.6

[12] Leckner, S. (2012). Presentation factors affecting reading behaviour in readers of newspaper media: an eye-tracking perspective. Visual Communication, 11(2), 163-184. https://doi.org/10.1177/1470357211434029

[13] Götz, V. (1998). Color \& type for the screen. Berlin RotoVision.

[14] Hunt, R. W. G. (2004). The reproduction of colour, sixth ed. Chicester: John Wiley \& Sons

[15] Josephson, S., \& Holmes, M. E. (2006). Clutter or content? Proceedings of the 2006 symposium on Eye tracking research \& applications - ETRA 06, 155-162. https://doi.org/10.1145/1117309.1117361

[16] Baetens, J. (2008). Colour as a visual signifier in screen typography: 'less means more'. Visual Studies, 23(3), $267-$ 274. https://doi.org/10.1080/14725860802489924

[17] Hasan, S. N., Muzammil, M., \& Khan, A. A. (2011). Effect of illumination, noise and text/background colour on spontaneous eye blink rate. Theoretical Issues in Ergonomics Science, 12(6), 514-532. https://doi.org/10.1080/14639221003736347

[18] Dzulkifli, M. A., \& Mustafar, M. F. (2013). The Influence of Colour on Memory Performance: A Review. The Malaysian Journal of Medical Sciences: MJMS, 20(2), 3-9.

[19] Pastoor, S. (1990). Legibility and Subjective Preference for Colour Combinations in Text. Human Factors, 32(2): 157171. https://doi.org/10.1177/001872089003200204

[20] Jessen, I. B., \& Graakjær, N. J. (2013). Cross-media communication in advertising: exploring multimodal connections between television commercials and websites. Visual Communication, 12(4), 437-458. https://doi.org/10.1177/1470357213497665

[21] Yue, S., Z. Jin, C. Fan, Zhang, Q. \& Li, L. (2017) Interference between smooth pursuit and color working memory. Journal of eye movement research, 10(3): 1-10. https://doi.org/10.16910/jemr.10.3.6

[22] NBC. (2016). NBC News, Available at http://www.nbcnews.com.

[23] ORF. (2016). ORF news, Available at http://orf-at.

[24] RTVSLO. (2016). MMC, first interactive multimedia portal, Available at http://www.rtvslo.si

[25] RTL Group. (2016). RTL, Available at http://www.rtl.de/ cms/index.html.

[26] SKY UK. (2016). SkyNews, Available at http://news.sky.com.

[27] Pro Plus. (2016). POP TV, Available at http://www.24ur.com/novice/.

[28] Wright, A. (1998). The Beginner's Guide to Colour Psychology. London: Colour Affects Ltd.
[29] Thussu, D. K. (2007). News as Entertainment, The rise of global infotainment. Sage Publications.

[30] Mehta, R. \& Zhu, J. (2009). Blue or red? Exploring the effect of color on cognitive task performances. PsycEXTRA Dataset, 1226-1229. https://doi.org/10.1037/e621092012-121

[31] Keyes, E. (1993). Typography, Color, and Information Structure. Technical Communication, Fourth Quarter, 638654

[32] Deirdre, K. (2003). Europe in the Media, A Comparison of Reporting, Representation, and Rhetoric in National Media Systems in Europe. European Institute for the Media.

[33] Fisher, D. F. (975). Reading and Visual Research. Memory \& Cognition, 3(2): 188-196.

[34] Josephson, S. (2008). Keeping Your Readers Eyes on the Screen: An Eye-Tracking Study Comparing Sans Serif and Serif Typefaces. Visual Communication Quarterly, 15(1-2), 67-79. https://doi.org/10.1080/15551390801914595

[35] Moret-Tatay, C. \& Perea, M. (2011). Do serifs provide an advantage in the recognition of written words? Journal of Cognitive Psychology, 23(5), 619-624. https://doi.org/10.1080/20445911.2011.546781

[36] Ali, A. Z., Wahid, R., Samsudin, K., \& Idris, M. Z. (2013). Reading on the Computer Screen: Does Font Type has Effects on Web Text Readability? International Education Studies, 6(3), 26-35. https://doi.org/10.5539/ies.v6n3p26

[37] Lund, O. (1999). Knowledge Construction in Typography: The Case of Legibility Research and the Legibility of Sans Serif Typefaces. Unpublished $\mathrm{PhD}$ dissertation, University of Reading, UK.

[38] Arditi, A. \& Cho, J. (2005). Serifs and font legibility. Vision Research, 45(23), 2926-2933. https://doi.org/10.1016/j.visres.2005.06.013

[39] Bernard, M. L., Chaparro, B. S., Mills, M. M., \& Halcomb, C. G. (2003). Comparing the effects of text size and format on the readibility of computer-displayed Times New Roman and Arial text. International Journal of Human-Computer Studies, 59(6), 823-835. https://doi.org/10.1016/s1071-5819(03)00121-6

[40] Pušnik, N., Podlesek, A., \& Možina, K. (2016). Typeface comparison - Does the x-height of lower-case letters increased to the size of upper-case letters speed up recognition? International Journal of Industrial Ergonomics, 54, 164-169. https://doi.org/10.1016/j.ergon.2016.06.002

[41] Stevens, M., \& Grainger, J. (2003). Letter visibility and the viewing position effect in visual word recognition. Perception \& Psychophysics, 65(1), 133-151. https://doi.org/10.3758/bf03194790

[42] Rayner, K., Slattery, T. J., \& Belanger, N. N. (2010). Eye movements, the perceptual span and readingspeed. Psychonomic Bulletin \& Review, 17(6), 834-839. https://doi.org/10.3758/PBR.17.6.834

[43] Huestegge, L., \&Radach, R. (2010). Visual and Memory Search in Complex Environments: Determinations of Eye Movements and Search Performance. Ergonomics, 55(9): 1009-1027. https://doi.org/10.1080/00140139.2012.689372

[44] Karim, A. K. \& Kojima, H. (2010). The what and why of perceptual asymmetries in the visual domain. Advances in Cognitive Psychology, 6(1), 103-115. https://doi.org/10.2478/v10053-008-0080-6

[45] Luccion, R., \&Caporusso, G. (2010). The Effect of the Context on the Anisotropy of the Visual Field. Review of Psychology, 17(1), 7-11

[46] Weisenmiler, E. M. (1999). A study of readability of onscreen text, PhD thesis, Virginia Polytechnic Institute and State University, Blacksburg.

[47] Garrod, S. \& Daneman, M. (2003). The Psychology of Reading. L. Nadel (Editor-in-Chief) Encyclopaedia of Cognitive Science, Vol. 6, 848-854. Nature Publishing Group, Macmillan Publishers, Ltd. 
[48] Yu, D., Cheung, S., Legge, G. E., \& Chung, S. T. (2007). Effect of letter spacing on visual span and reading speed. Journal of Vision, 7(2), 2. https://doi.org/10.1167/7.2.2

[49] Lund, O. (1997). Why serifs are (still) important. Typography Papers, 2, 91-104.

[50] Lund, O. (1998). Type \& layout: how typography and design can get your message across - or get in the way. Information Design Journal, 9(1), 74-77. https://doi.org/10.1075/idj.9.1.18lun

[51] Bouwhuis, D. \& Bouma, H. (1979). Visual word recognition of three-letter words as derived from the recognition of the constituent letters. Perception \& Psychophysics, 25(1), 1222. https://doi.org/10.3758/bf03206104

[52] Aberson, D. H., \& Bouwhuis, D. G. (1997). Silent Reading as Determined by Age and Visual Acuity. Journal of Research in Reading, 20(3), 184-204. https://doi.org/10.1111/1467-9817.00032

[53] Ponce, H. R. \& Mayer, R. E. (2014). An eye movement analysis of highlighting and graphic organizer study aids for learning from expository text. Computers in Human Behavior, 41, 21-32. https://doi.org/10.1016/j.chb.2014.09.010

[54] Kovačević, D., Brozović, M., \& Možina， K. (2016). Improving visual search in instruction manuals using pictograms*. Ergonomics, 59(11), 1405-1419. https://doi.org/10.1080/00140139.2016.1142123

[55] Humar, I., Gradisar, M., Turk, T., \& Erjavec, J. (2014). The impact of color combinations on the legibility of text presented on LCDs. Applied Ergonomics, 45(6), 1510-1517. https://doi.org/10.1016/j.apergo.2014.04.013

[56] McCalley, L. T. (1995). Visual selective attention and aging (chapter 4), PhD thesis, Technische Universiteis Eindhoven, Eindhoven.

[57] International standard ISO 3664:2009 (E). Graphic Technology and Photography - Viewing Conditions. Geneva, Switzerland.

[58] International standard ISO 9241-307:2008. Ergonomics of Human-System Interaction - Part307: Analysis and Compliance Test Methods for Electronic Visual Displays. Geneva, Switzerland.

[59] Faulkner, L. (2003). Beyond the five-user assumption: Benefits of increased sample sizes in usability testing. Behavior Research Methods, Instruments, \& Computers, 35(3), 379-383. https://doi.org/10.3758/bf03195514

[60] Schmettow, M. (2012). Sample size in usability studies. Communications of the ACM, 55(4), 64-70. https://doi.org/10.1145/2133806.2133824

[61] Eraslan, S., Yesilada, Y., \& Harper, S. (2017). Less users more confidence: How AOIs don't affect scan path trend analysis. Journal of eye movement research, 10(4), 6 . https://doi.org/10.16910/jemr.10.4.6

[62] Leube, A., Rifai, K., \& Wahl, S. (2017). Sampling rate influences saccade detection in mobile eye tracking of a reading task. Journal of eye movement research, 10(3), 1-11. https://doi.org/10.16910/jemr.10.3.3

[63] Carlson, T. A., Hogendoorn, H., \&Verstraten, A. J. (2006). The speed of visual attention: What time is it? Journal of Vision, 6, 1406-1411. https://doi.org/10.1167/6.12.6

[64] Arend, L. E. \& Spehar, B. (1993). Lightness, brightness, and brightness contrast: 1 . Illuminance variation. Perception \& Psychophysics, 54(4), 446-456. https://doi.org/10.3758/bf03211767

[65] Backhaus, W. G., Kliegl, R., \& Werne, J. S. (1998). Color vision: perspectives from different disciplines. Berlin: De Gruyter.

[66] Lin, C. (2003). Effects of contrast ratio and text color on visual performance with TFT-LCD. International Journal of Industrial Ergonomics, 31(2), 65-72. https://doi.org/10.1016/s0169-8141(02)00175-0
[67] Ojanpää, H. \& Näsänen, R. (2003). Effects of luminance and colour contrast on the search of information on display devices. Displays, 24(4-5), 167-178. https://doi.org/10.1016/j.displa.2004.01.003

\section{Contact information}

Nace PUŠNIK, Assistant Professor, PhD (Corresponding Author)

University of Ljubljana, Faculty of Natural Sciences and Engineering,

Department of Textiles, Graphic Arts and Design

Snežniška 5, 1000 Ljubljana, Slovenia

nace.pusnik@ntf.uni-lj.si

Anja PODLESEK, Associate Professor, PhD

University of Ljubljana, Faculty of Arts,

Department of Psychology

Aškerčeva 2, 1000 Ljubljana, Slovenia

anja.podlesek@ff.uni-lj.si

Uroš NEDELJKOVIĆ, Associate Professor, PhD University of Novi Sad, Faculty of Technical Sciences,

Department of Graphic Engineering and Design

Trg Dositeja Obradovića 6, 21000 Novi Sad, Serbia

urosned@UNS.AC.RS

Klementina MOŽINA, Professor, PhD

University of Ljubljana, Faculty of Natural Sciences and Engineering, Department of Textiles, Graphic Arts and Design

Snežniška 5, 1000 Ljubljana, Slovenia

klementina.mozina@ntf.uni-lj.s 